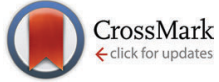

Cite this: Chem. Commun., 2016, 52,689

Received 4th October 2015,

Accepted 6th November 2015

DOI: $10.1039 / \mathrm{c} 5 \mathrm{cc} 08265 j$

www.rsc.org/chemcomm

\section{Synthesis, structure and bonding of hexaphenyl thorium(Iv): observation of a non-octahedral structure $\dagger$}

\author{
Elizabeth A. Pedrick, ${ }^{a}$ Peter Hrobárik, *b Lani A. Seaman, ${ }^{a}$ Guang Wu ${ }^{a}$ and \\ Trevor W. Hayton*a
}

\begin{abstract}
We report herein the synthesis of the first structurally characterized homoleptic actinide aryl complexes, $\left[\mathrm{Li}(\mathrm{DME})_{3}\right]_{2}\left[\mathrm{Th}\left(\mathrm{C}_{6} \mathrm{H}_{5}\right)_{6}\right](1)$ and [Li(THF)(12-crown-4) $]_{2}\left[T h\left(\mathrm{C}_{6} \mathrm{H}_{5}\right)_{6}\right]$ (2), which feature an anion possessing a regular octahedral (1) or a severely distorted octahedral (2) geometry. The solid-state structure of 2 suggests the presence of pseudo-agostic ortho $\mathrm{C}-\mathrm{H} \cdots$ Th interactions, which arise from $\sigma(\mathrm{C}-\mathrm{H}) \rightarrow \operatorname{Th}(5 \mathrm{f})$ donation. The non-octahedral structure is also favoured in solution at low temperatures.
\end{abstract}

High-valent homoleptic transition metal complexes of the type $\left[\mathrm{MR}_{6}\right]^{q}(\mathrm{R}=$ alkyl, aryl; $q=0,-1,-2)$ have proven to be incredibly useful for exploring the nature of the $\mathrm{M}-\mathrm{C}$ bond..$^{1-5}$ In particular, the observation of a trigonal prismatic structure for these complexes, as opposed to the more common octahedral geometry, is considered strong evidence for the involvement of the d orbitals in the metal-carbon bonds. ${ }^{2,3}$ A number of trigonal prismatic $\left[\mathrm{MR}_{6}\right]^{q_{-}}$ type complexes have been structurally characterized, including $[\mathrm{Li}(\mathrm{TMEDA})]_{2}\left[\mathrm{Zr}\left(\mathrm{CH}_{3}\right)_{6}\right],{ }^{6}\left[\mathrm{M}\left(\mathrm{CH}_{3}\right)_{6}\right]^{q} \quad(\mathrm{M}=\mathrm{W}, \mathrm{Re}, \mathrm{Nb}, \mathrm{Ta}$; $q=0,-1),{ }^{4}\left[\mathrm{Ta}\left(\mathrm{C} \equiv \mathrm{CSi}_{\mathrm{Bu}}\right)_{6}\right]^{-{ }^{7}}\left[\mathrm{M}\left(\mathrm{C}_{6} \mathrm{H}_{5}\right)_{6}\right]^{2-}(\mathrm{M}=\mathrm{Zr}, \mathrm{Nb}),{ }^{8}$ and $\left[\mathrm{Ta}\left(\mathrm{C}_{6} \mathrm{H}_{5}\right)_{6}\right]^{-9}{ }^{9}$ Notably absent from this list, however, are their heavier actinide analogues. This paucity is notable, as structural characterization of $\left[\mathrm{AnR}_{6}\right]^{q}$ complexes would provide a unique platform to study the involvement of the $6 \mathrm{~d}$ and $5 \mathrm{f}$ orbitals in An-C bonds. In this regard, we, and others, have made several attempts to isolate homoleptic alkyl complexes of thorium $^{10,11}$ and uranium. ${ }^{12-15}$ Despite considerable synthetic efforts, previous attempts have resulted in the isolation and structural characterization of only three homoleptic Th alkyl complexes, namely, the 5-coordinate complex $\left[\mathrm{Li}(\mathrm{THF})_{4}\right]\left[\mathrm{Th}\left(\mathrm{CH}_{2} t \mathrm{Bu}\right)_{5}\right]{ }^{10}$

\footnotetext{
${ }^{a}$ Department of Chemistry and Biochemistry, University of California, Santa Barbara, CA 93106, USA. E-mail: hayton@chem.ucsb.edu

${ }^{b}$ Institut für Chemie, Technische Universität Berlin, Strasse des 17. Juni 135, 10623 Berlin, Germany. E-mail: peter.hrobarik@tu-berlin.de

$\dagger$ Electronic supplementary information (ESI) available: Experimental procedures and computational details, characterization, crystallographic and quantumchemical calculation data as well as NMR spectra. CCDC 1428924-1428925. For ESI and crystallographic data in CIF or other electronic format see DOI: 10.1039/ c5cc08265j
}

and two 7-coordinate complexes, [Li(TMEDA) $]_{3}\left[\mathrm{Th}\left(\mathrm{CH}_{3}\right)_{7}\right]^{11}$ and $[\mathrm{K}(\mathrm{THF})]_{2}\left[\mathrm{Th}\left(\mathrm{CH}_{2} \mathrm{Ph}\right)_{6}\right]{ }^{10}$ where the latter features an $\eta^{2}$ interaction for one of its benzyl ligands. Similarly, only a few 6-coordinate homoleptic U alkyl complexes are known, namely [Li(TMEDA) $]_{2}$ $\left[\mathrm{U}\left(\mathrm{CH}_{3}\right)_{6}\right],\left[\mathrm{K}(\mathrm{THF})_{3}\left[\mathrm{~K}(\mathrm{THF})_{2}\right]\left[\mathrm{U}\left(\mathrm{CH}_{2} \mathrm{Ph}\right)_{6}\right]_{2}\right.$, and $\left[\mathrm{Li}(\mathrm{THF})_{4}\right]\left[\mathrm{U}\left(\mathrm{CH}_{2}-\right.\right.$ $\left.\left.\mathrm{SiMe}_{3}\right)_{6}\right]^{12,13}$ The latter was oxidized in situ to $\mathrm{U}\left(\mathrm{CH}_{2} \mathrm{SiMe}_{3}\right)_{6}$, which was characterized using ${ }^{13} \mathrm{C}$ and ${ }^{1} \mathrm{H}$ NMR spectroscopies, accompanied by relativistic DFT calculations of NMR chemical shifts. ${ }^{16}$ In each uranium example, an octahedral geometry was observed, which is perhaps not surprising, as significant f-orbital participation in bonding tends to favor an octahedral geometry. ${ }^{17}$ In contrast, $\mathrm{d}$ orbital involvement in Th-C bonding is expected to be more significant than $\mathrm{f}$ orbital participation, ${ }^{18,19}$ and therefore the observation of a trigonal prismatic structure should be more likely for this element relative to the other actinides. ${ }^{10}$ Given this consideration, we endeavored to synthesize and structurally characterize the homoleptic actinide-aryl complex, $\left[\mathrm{Th}\left(\mathrm{C}_{6} \mathrm{H}_{5}\right)_{6}\right]^{2-}$, by reacting $\mathrm{ThCl}_{4}$ with an excess of phenyl lithium.

Addition of 8 equiv. of PhLi to a THF solution of $\mathrm{ThCl}_{4}(\mathrm{DME})_{2}$ results in the formation of a white solid and a dark amber solution. Isolation of this amber material, followed by recrystallization from concentrated DME, afforded $\left[\mathrm{Li}(\mathrm{DME})_{3}\right]_{2}\left[\mathrm{Th}\left(\mathrm{C}_{6} \mathrm{H}_{5}\right)_{6}\right](\mathbf{1})$ as a pale yellow crystalline material in 56\% yield (Scheme 1). Complex 1 is thermally unstable at room temperature (RT), both as a solid and in solution, but is stable for up to 2 weeks as a solid at $-25{ }^{\circ} \mathrm{C}$. It is insoluble in hexane, aromatic solvents, and diethyl ether, but very soluble in THF and DME. Its ${ }^{1} \mathrm{H}$ NMR spectrum in THF- $d_{8}$ at RT reveals resonances at $7.61 \mathrm{ppm}, 7.00 \mathrm{ppm}$ and $6.79 \mathrm{ppm}$ in the ratio of $2: 2: 1$, corresponding to the ortho, meta, and para protons of the phenyl ring, respectively. In addition, there is a single resonance in its ${ }^{7} \mathrm{Li}\left\{{ }^{1} \mathrm{H}\right\}$ NMR spectrum at $2.60 \mathrm{ppm}$. The ${ }^{13} \mathrm{C}\left\{{ }^{1} \mathrm{H}\right\}$ NMR spectrum in THF- $d_{8}$ exhibits a key fingerprint resonance at $220.5 \mathrm{ppm}$, which corresponds to the ipso-carbon, as also confirmed by our relativistic DFT calculations of the NMR chemical shifts ( $c f$. Table S2 in the $\mathrm{ESI} \dagger$ ). This resonance is shifted notably downfield from the corresponding ${ }^{13} \mathrm{C}$-ipso shifts in related $\mathrm{Ti}, \mathrm{Zr}$, and $\mathrm{Hf}$ aryl complexes (which typically appear between 183 and $198 \mathrm{ppm}$ ), ${ }^{20}$ which can be attributed to a substantial spin-orbit (SO)-induced deshielding 


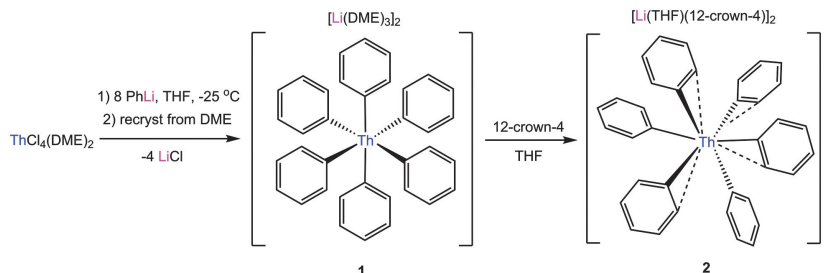

Scheme 1 Reaction of $\mathrm{ThCl}_{4}$ with an excess of phenyl lithium.

$\left(\delta_{\text {SO }}>30 \mathrm{ppm}\right)$ of $\sigma$-bonded carbon nuclei to $\mathrm{f}^{0}$ actinide center. ${ }^{16,21}$ The other ${ }^{13} \mathrm{C}$ aryl signals are observed at 136.9, 126.6 and $125.2 \mathrm{ppm}$, and are assignable to ortho, meta and para carbon atoms of the phenyl ring, respectively.

Complex 1 crystallizes in the trigonal space group $R \overline{3}$, and its solid-state molecular structure is shown in Fig. 1 (top). The thorium-containing anion resides on a special position such that there is only one crystallographically unique phenyl group. As a result, the geometry about the Th center is a near perfect octahedron, with a Th1-C1 bond length of 2.589(3) ̊. This value

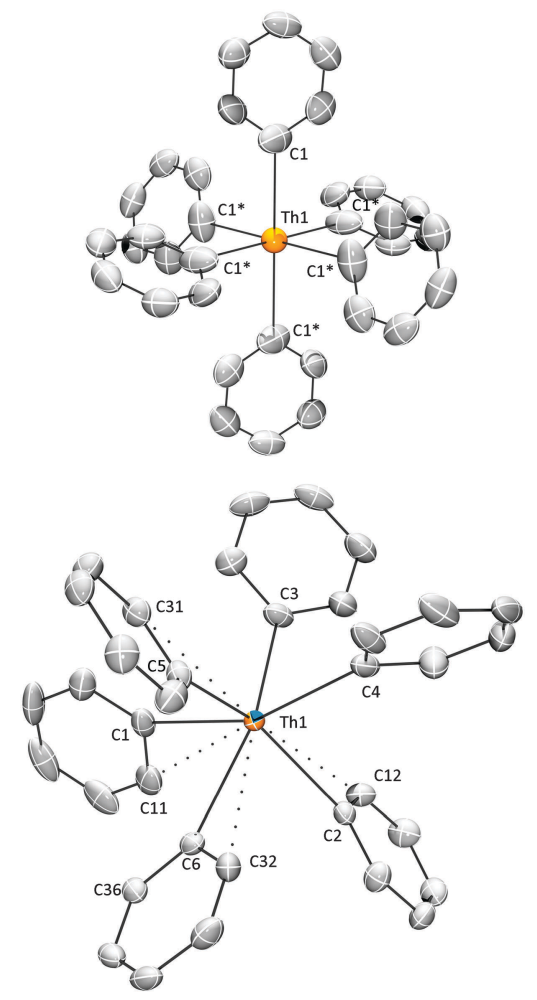

Fig. 1 ORTEP diagram of $\left[\mathrm{Li}(\mathrm{DME})_{3}\right]_{2}\left[\mathrm{Th}\left(\mathrm{C}_{6} \mathrm{H}_{5}\right)_{6}\right](\mathbf{1}$, top) and [Li(THF)(12crown-4) $]_{2}\left[T h\left(\mathrm{C}_{6} \mathrm{H}_{5}\right)_{6}\right]$ (2, bottom); thermal ellipsoids set at $50 \%$ probability, cations and hydrogen atoms are omitted for clarity. Asterisks denote symmetry related atoms. Selected bond lengths [Å] and angles [deg]: 1 : Th1-C1 $=2.589(3)$, C1-Th1-C1* $=180, C 1-T h 1-C 1^{*}=89.1(1), C 1-T h 1-C 1^{*}=90.9(1) .2$ : Th1 $-\mathrm{C} 1=2.620(3)$, Th1 $-\mathrm{C} 2=2.553(3)$, Th1 $-\mathrm{C} 3=2.636(3)$, Th1-C4 = 2.648(3), Th1-C5 = 2.557(3), Th1-C6 = 2.605(3), C1-Th1-C2 = 110.5(1), C1Th1-C3 = 78.1(1), C1-Th1-C4 = 159.0(1), C1-Th1-C5 = 93.2(1), C1-Th1-C6 = 79.1(1), Th1 $-\mathrm{C} 1-\mathrm{C} 11=108.7(2), \mathrm{Th} 1-\mathrm{C} 1-\mathrm{C} 7=137.2(3), \mathrm{Th} 1-\mathrm{C} 2-\mathrm{C} 12=108.8(2)$, Th1 $-\mathrm{C} 2-\mathrm{C} 16=136.4(2)$, Th1 $-\mathrm{C} 3-\mathrm{C} 17=113.2(3)$, Th1 $-\mathrm{C} 3-\mathrm{C} 21=121.8(3)$, Th1 $\mathrm{C} 4-\mathrm{C} 22=117.0(3)$, Th1 $-\mathrm{C} 4-\mathrm{C} 26=129.8(3)$, Th1 $-\mathrm{C} 5-\mathrm{C} 31=109.7(2)$, Th1 $-\mathrm{C} 5-$ $\mathrm{C} 27=135.4(3), \mathrm{Th} 1-\mathrm{C} 6-\mathrm{C} 32=104.4(2), \mathrm{Th1}-\mathrm{C} 6-\mathrm{C} 36=141.3(2)$. is typical of Th-C bonds, ${ }^{10-11,22}$ and agrees well with those optimized at the DFT level (Table 1). Additionally, there are two $\left[\mathrm{Li}(\mathrm{DME})_{3}\right]^{+}$ cations per $\left[\mathrm{Th}\left(\mathrm{C}_{6} \mathrm{H}_{5}\right)_{6}\right]^{2-}$ anion, and these feature no obvious interaction with that moiety.

Interestingly, the addition of 1 equiv. of 12 -crown- 4 to a THF solution of 1 results in a new material, [Li(THF)(12-crown-4)] $2_{2}^{-}$ $\left[\mathrm{Th}\left(\mathrm{C}_{6} \mathrm{H}_{5}\right)_{6}\right]$ (2), which can be isolated as a light tan crystalline solid in $44 \%$ yield (Scheme 1). Complex 2 is less thermally stable than complex 1. It is stable as a solid for about a week at $-25^{\circ} \mathrm{C}$ under an inert atmosphere, however, as a solution at $-25{ }^{\circ} \mathrm{C}$, complex 2 exhibits partial decomposition after $10 \mathrm{~min}$, as evidenced by the formation of benzene. The ${ }^{1} \mathrm{H}$ NMR spectrum of 2 at RT features aryl resonances that are essentially identical to those of 1. In addition, an intense singlet is observed at $3.38 \mathrm{ppm}$, which is assignable to the 12-crown- 4 moiety.

Complex 2 crystallizes in the monoclinic space group $P 2_{1} / n$, and its solid-state molecular structure is shown in Fig. 1 (bottom). Unlike 1, complex 2 exhibits a severely distorted octahedral geometry, although no close contact between the $\left[\mathrm{Th}\left(\mathrm{C}_{6} \mathrm{H}_{5}\right)_{6}\right]^{2-}$ moiety and the counterions are apparent. For example, the smallest $\mathrm{C}-\mathrm{Th}-\mathrm{C}$ angle is $\mathrm{C} 1-\mathrm{Th} 1-\mathrm{C} 3=78.1(1)^{\circ}$, while the largest C-Th-C angle is $\mathrm{C} 1-\mathrm{Th} 1-\mathrm{C} 4=159.0(1)^{\circ}$. The Th-C bond lengths range from $\mathrm{Th} 1-\mathrm{C} 2=2.553(3) \AA$ to $\mathrm{Th} 1-\mathrm{C} 3=2.636(3) \AA$, and are comparable to those optimized for $\left[\mathrm{Th}\left(\mathrm{C}_{6} \mathrm{H}_{5}\right)_{6}\right]^{2-}$ with $C_{3}$ and $C_{3}{ }^{\prime}$ symmetry (Table 1). Perhaps more interestingly, several of the $\mathrm{Ph}$ ligands in complex 2 feature relatively acute $\mathrm{M}-\mathrm{C}_{i p s o}-\mathrm{C}_{\text {ortho }}$ bond angles $\left(\sim 104-110^{\circ}\right)$ and short $\mathrm{Th} \cdots \mathrm{H}_{\text {ortho }}$ contacts $(\sim 3.01-3.14 \AA$; estimated using $\mathrm{C}-\mathrm{H}$ bond lengths of $0.99 \AA),{ }^{23}$ which are suggestive of pseudo-agostic (anagostic) interactions. ${ }^{24}$ For example, the Th1-C6-C32 bond angle is 104.4(2) ${ }^{\circ}$, while the Th1-C6-C36 bond angle is $141.3(2)^{\circ}$, a difference of $37^{\circ}$. Three other phenyl groups (namely, C1, C2, and C5) in complex 2 also appear to feature ortho $\mathrm{C}-\mathrm{H}$ anagostic interactions, although not as strong as those observed for the C6 phenyl ligand.

To better evaluate the geometry about the Th center in complex 2, we determined its Continuous Shape Measure (CSM). ${ }^{25}$ The CSM analysis generates a pair of coordinates $\left\{S(\mathrm{TPM}), S\left(\mathrm{O}_{\mathrm{h}}\right)\right\}$, from which a qualitative determination of the structure can be made. According to the CSM, a value of $\{16.7,0\}$ is expected for a perfect octahedron (as found, e.g. for $\mathbf{1}$ ), while a value of $\{0,16.7\}$ is expected for a perfect trigonal prism. Complex 2 features CSM coordinates of $\{4.83,6.17\}$. These parameters suggest that the geometry of 2 lies at a point intermediate between that of an ideal octahedron and an ideal trigonal prism. However, they also indicate that 2 deviates somewhat from the Bailar trigonal twist pathway commonly observed for 6-coordinate complexes. ${ }^{25}$ No doubt, the challenge of describing the structure of $\mathbf{2}$ is the result of interactions between the metal center and $\mathrm{C}-\mathrm{H}$ bonds of the Ph ligands.

Clearly, the energy difference between the structures of $\mathbf{1}$ and $\mathbf{2}$ must be small, given that different crystal packing can result in one structure being favored over the other. Nonetheless, the solution spectroscopic properties of $\mathbf{1}$ were examined with greater scrutiny (see Fig. S4 in the ESI $\dagger$ for variable temperature NMR spectra of 1 in THF- $d_{8}$ ) in an attempt to observe this structural perturbation in solution. Interestingly, upon cooling to $-90{ }^{\circ} \mathrm{C}$, the phenyl resonances decoalesce into five separate peaks, with $\delta\left({ }^{1} \mathrm{H}\right)$ at 7.84, 7.16, 
Table 1 Relative energies, selected structural parameters and analysis of the $M-C$ bonds in $\left[M^{I V}\left(C_{6} H_{5}\right)_{6}\right]^{2-}$ complexes $(M=Z r$, $H f$, Th) with different symmetry

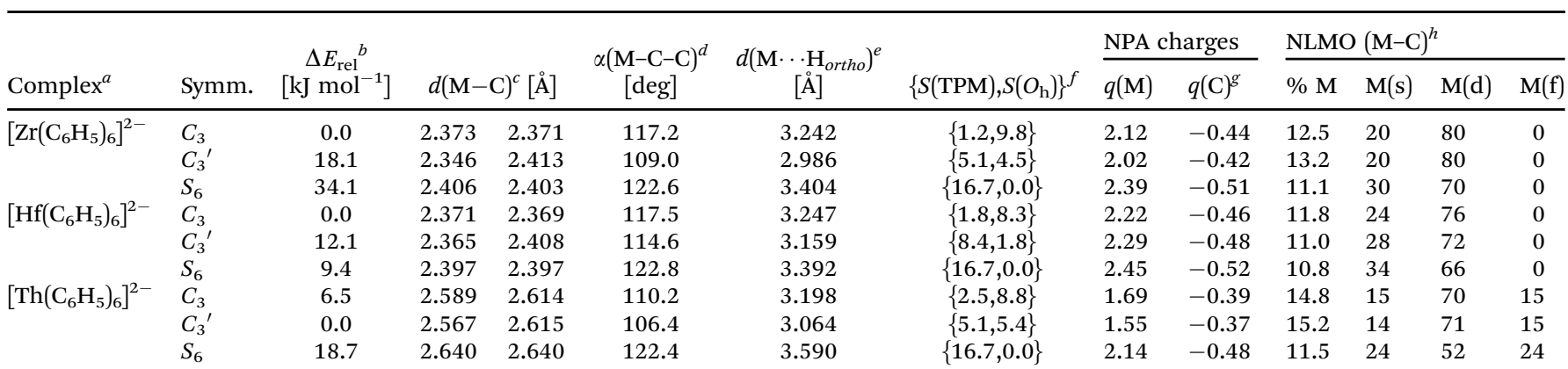

${ }^{a}$ PBE0-D3(BJ)/ECP/def2-TZVP results (see Computational methods in the ESI). ${ }^{b}$ Relative zero-point corrected electronic energies. ${ }^{c} \mathrm{M}-\mathrm{C}_{i p s o}$ bond lengths. ${ }^{d}$ The most acute $\alpha\left(\mathrm{M}-\mathrm{C}_{i p s o}-\mathrm{C}_{\text {ortho }}\right)$ angle. ${ }^{e}$ The shortest $d\left(\mathbf{M} \cdots \mathrm{H}_{\text {ortho }}\right)$ contact. ${ }^{f}$ CSM coordinates evaluated for the [MC ${ }_{6}$ core unit (see the text and Computational methods in the ESI). ${ }^{g}$ NPA charges averaged over all $\mathrm{C}_{i p s o}$ atoms. ${ }^{h}$ The averaged metal and metal AO contributions (in \%) to the $\sigma(\mathrm{M}-\mathrm{C})$ bonding NLMOs.

7.01, 6.78, and $6.60 \mathrm{ppm}$, which we have tentatively assigned to the five proton environments anticipated for a $C_{3}$ symmetric structure with restricted Th-C bond rotation. Alternatively, the five proton environments can be assigned to a phenyl group involved in a static anagostic interaction. Either interpretation suggests that a nonoctahedral structure, similar to that observed for 2 in the solidstate, is present in solution at very low temperatures. Further support for this interpretation comes from the good agreement between the experimental ${ }^{1} \mathrm{H}$ NMR spectrum and the calculated ${ }^{1} \mathrm{H}$ NMR shifts for the $C_{3}$ and $C_{3}{ }^{\prime}$ structures (Table S3, ESI $\dagger$ ). Finally, using the two-site exchange approximation, ${ }^{26}$ the activation barrier $\left(\Delta G_{\mathrm{C}}^{\ddagger}\right)$ for ortho $\mathrm{CH}$ exchange was calculated to be $40 \mathrm{~kJ} \mathrm{~mol}^{-1}$, however this value should be considered an upper limit, as the broadness of the $-90{ }^{\circ} \mathrm{C}$ spectrum prohibits an accurate determination of $\Delta \nu$.

To gain better insight into their structural preferences, we performed quasi-relativistic DFT calculations on the naked $\left[\mathrm{ThR}_{6}\right]^{2-}$ $\left(\mathrm{R}=\mathrm{CH}_{3}, \mathrm{C}_{6} \mathrm{H}_{5}\right)$ anions and the results were contrasted with those of the isoelectronic $\mathrm{Zr}(\mathrm{IV})$ and $\mathrm{Hf}(\mathrm{IV})$ congeners, as well as of the group 5 homologues (the salient structural parameters, along with relative energies of individual geometries, are collected in Table 1 and Tables $\mathrm{S} 4$ and S5 in the ESI $\dagger$ ). In general, NPA charges and composition of $\sigma(\mathrm{M}-\mathrm{C})$ bonding NLMOs within the $\left[\mathrm{M}\left(\mathrm{C}_{6} \mathrm{H}_{5}\right)_{6}\right]^{2-}(\mathrm{M}=\mathrm{Zr}, \mathrm{Hf}, \mathrm{Th})$ series indicate strongly polar nature of the $\mathrm{M}-\mathrm{C}$ bonds (with the metal percentage contribution ranging from $10 \%$ (Hf) to $15 \%(\mathrm{Th})$ ), with somewhat less ionic character for Th, as well as increased covalency upon changing an octahedral geometry to the energetically more favorable (distorted) prismatic structure. While hexamethyl $\left[\mathrm{M}\left(\mathrm{CH}_{3}\right)_{6}\right]^{2-}$ complexes display only two distinct stationary points on the potential energy hypersurface, corresponding to the octahedral $\left(S_{6}\right)$ and prismatic $\left(D_{3 \mathrm{~h}}\right)$ geometries, we have found three for the hexaaryl series ( $S_{6}, C_{3}$ and $C_{3}{ }^{\prime}$; see Fig. 2, top). The $\mathrm{MC}_{6}$ unit in $C_{3}$ geometry of $\left[\mathrm{M}\left(\mathrm{C}_{6} \mathrm{H}_{5}\right)_{6}\right]^{2-}$ can be viewed as ideal or slightly distorted trigonal prism, while $C_{3}{ }^{\prime}$ structure is intermediate between octahedral and trigonal prismatic geometries (but still maintaining the $C_{3}$ axis; see also CSM coordinates in Table 1). In the latter, three $\mathrm{Ph}$ rings of $\left[\mathrm{M}\left(\mathrm{C}_{6} \mathrm{H}_{5}\right)_{6}\right]^{2-}$ moieties feature more acute $\mathrm{M}-\mathrm{C}_{i p s o}-\mathrm{C}_{\text {ortho }}$ bond angles $\left(<110^{\circ}\right)$ and shorter $\mathrm{M} \cdots \mathrm{H}_{\text {ortho }}$ contacts than found for $C_{3}$ structures ( $c f$. Table 1), consistent with anagostic interactions observed in the X-ray structure of $2 .{ }^{27}$ More importantly, while the $C_{3}{ }^{\prime}$ structure is found as the global minimum for $\left[\mathrm{Th}\left(\mathrm{C}_{6} \mathrm{H}_{5}\right)_{6}\right]^{2-}$, this severely distorted geometry is energetically disfavored over the $C_{3}$ prismatic structure in transition-metal complexes (more so for Zr than for Hf analogue).

According to natural bond orbital (NBO) second-order perturbation energy analysis, ${ }^{28}$ stabilization of the $C_{3}{ }^{\prime}$ geometry can be ascribed to the donor-acceptor interaction between $\sigma\left(\mathrm{C}_{\text {ortho }}-\mathrm{H}\right)$ occupied MOs and the vacant, predominantly metal-centered MOs with a significant 5 f character (see Fig. 2 and Table S6 in the ESI $\dagger){ }^{29}$

This ortho $\mathrm{C}-\mathrm{H}$ anagostic interaction is apparently absent in transition-metal hexaaryl complexes, and it is notably weaker than the agostic Th $\cdots \mathrm{H}-\mathrm{C}$ interaction in $\mathrm{H}_{2} \mathrm{C}=\mathrm{ThH}_{2}{ }^{30}(c f$. Table S6 in the ESI $\dagger$ ). Nevertheless, it facilitates the stabilization of the severely distorted $C_{3}{ }^{\prime}$ structure and enlarges the gap between non-octahedral minima and octahedral states by more than $9 \mathrm{~kJ} \mathrm{~mol}^{-1}$ as compared to $\left[\mathrm{HfR}_{6}\right]^{2-}$ and $\left[\mathrm{Th}\left(\mathrm{CH}_{3}\right)_{6}\right]^{2-}(c f$. Table 1 and Tables S4 and S5 in the ESI $\dagger$ ). In addition, removing $\mathrm{f}$ functions in the basis set of Th (the $4 \mathrm{f}$ shell is included in the

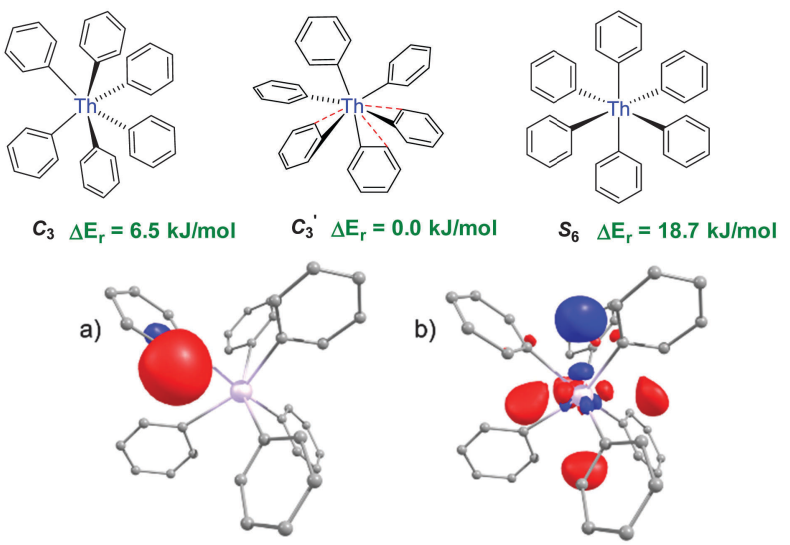

Fig. 2 Top: Schematic structures of different geometries of $\left[\mathrm{ThPh}_{6}\right]^{2-}$. Bottom: Isosurface plots (cutoff: \pm 0.05 a.u.) for the (a) $\sigma\left(\mathrm{C}_{\text {ortho }}-\mathrm{H}\right)$ donor and (b) acceptor NBOs associated with the anagostic Th...H- $\mathrm{C}_{\text {ortho }}$ interactions (indicated by red dashed-lines; $\mathrm{H}$ atoms are omitted for clarity). 
pseudopotential core) leads to a significant destabilization of

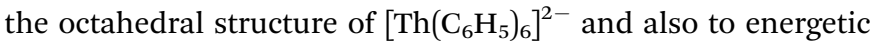
preference of the $C_{3}$ geometry over $C_{3}{ }^{\prime}$ ( $c f$. Table S5 in the ESI $\dagger$ ), demonstrating the important role of $\mathrm{Th}(5 \mathrm{f})$ orbitals in structure preferences despite their modest involvement in Th-C bonding (cf. Table 1). Similar structural trends are also found in the group 5 hexaaryl complexes, $\left[\mathrm{M}\left(\mathrm{C}_{6} \mathrm{H}_{5}\right)_{6}\right]^{-}(\mathrm{M}=\mathrm{Nb}, \mathrm{Ta}, \mathrm{Pa})$, where the ortho $\mathrm{C}-\mathrm{H}$ anagostic interactions stabilize the severely distorted $C_{3}{ }^{\prime}$ structure of the hypothetical $\left[\mathrm{Pa}\left(\mathrm{C}_{6} \mathrm{H}_{5}\right)_{6}\right]^{-}$complex, while $\left[\mathrm{Pa}\left(\mathrm{CH}_{3}\right)_{6}\right]^{-}$is predicted to adopt a regular octahedral geometry (cf. Tables S4 and S5 in the ESI $\dagger$ ).

Despite the specific interactions discussed above, the difference in energy between various geometries of $\mathrm{Th}$, and in particular $\mathrm{Hf}$, hexaphenyl complexes is quite small $\left(<20 \mathrm{~kJ} \mathrm{~mol}^{-1}\right)$, as we surmised above. We also note that the related $\left[\mathrm{Hf}\left(\mathrm{C}_{6} \mathrm{H}_{5}\right)_{6}\right]^{2-}$ anion also features different coordination geometries as a function of the identity of its counterion. ${ }^{8}$ For instance, $\left[\mathrm{Li}(\mathrm{THF})_{4}\right]_{2^{-}}$ $\left[\mathrm{Hf}\left(\mathrm{C}_{6} \mathrm{H}_{5}\right)_{6}\right]$ exhibits an ideal octahedral geometry, while [ $\left.\mathrm{Li}(\mathrm{THF})_{4}\right]-$ $[\mathrm{Li}(\mathrm{THF})]\left[\mathrm{Hf}\left(\mathrm{C}_{6} \mathrm{H}_{5}\right)_{6}\right]$ features an irregular structure, which is, however, also not far away from octahedral (see Table $\mathrm{S} 7$ in the $\mathrm{ESI} \dagger$ for CSM analysis). Moreover, distortion of the latter is most likely caused by close contact of $[\mathrm{Li}(\mathrm{THF})]^{+}$ion with three $\mathrm{Ph}$ groups, which is not the case in complex 2.

In conclusion, $\left[\mathrm{Th}\left(\mathrm{C}_{6} \mathrm{H}_{5}\right)_{6}\right]^{2-}$ is a rare example of an $\mathrm{f}$ orbitaldriven geometry. While a large ionic radius of $\mathrm{Th}^{4+}$ and the larger $\mathrm{Th}-\mathrm{C}$ bond covalency as compared to $\mathrm{Zr} / \mathrm{Hf}$ homologues reduce the repulsion between negatively charged ligands, and thus tend to prefer a prismatic structure, involvement of $5 \mathrm{f}$ orbitals in Th-C bonding acts oppositely, in favor of the octahedral coordination. Concurrently, $\sigma(\mathrm{C}-\mathrm{H}) \rightarrow \mathrm{Th}(5 \mathrm{f})$ donation comes into play and determines the severely distorted octahedral structure as the global minimum.

This work was supported by the U.S. Department of Energy, Office of Basic Energy Sciences, Division of Chemical Sciences, Biosciences, and Geosciences, under Contract No. DE-FG0209ER16067. P. H. acknowledges support from the Berlin DFG excellence cluster on "Unifying Concepts in Catalysis" (UniCat).

\section{Notes and references}

1 (a) A. Demolliens, Y. Jean and O. Eisenstein, Organometallics, 1986, 5, 1457; (b) S. K. Kang, T. A. Albright and O. Eisenstein, Inorg. Chem., 1989, 28, 1611.

2 (a) M. Kaupp, J. Am. Chem. Soc., 1996, 118, 3018; (b) M. Kaupp, Chem. - Eur. J., 1998, 4, 1678; (c) M. Kaupp, Angew. Chem., Int. Ed., 2001, 40, 3534.

3 K. Seppelt, Acc. Chem. Res., 2003, 36, 147.

4 (a) V. Pfennig and K. Seppelt, Science, 1996, 271, 626; (b) S. Kleinhenz, V. Pfennig and K. Seppelt, Chem. - Eur. J., 1998, 4, 1687.

5 (a) C. R. Landis, T. Cleveland and T. K. Firman, Science, 1996, 272, 182; (b) C. R. Landis, T. K. Firman, D. M. Root and T. Cleveland, J. Am. Chem. Soc., 1998, 120, 1842.

6 P. M. Morse and G. S. Girolami, J. Am. Chem. Soc., 1989, 111, 4114.
7 T. P. Vaid, A. S. Veige, E. B. Lobkovsky, W. V. Glassey, P. T. Wolczanski, L. M. Liable-Sands, A. L. Rheingold and T. R. Cundari, J. Am. Chem. Soc., 1998, 120, 10067.

8 S. El-Kurdi and K. Seppelt, Chem. - Eur. J., 2011, 17, 3956.

9 S. Kleinhenz, M. Schubert and K. Seppelt, Chem. Ber., 1997, 130, 903.

10 L. A. Seaman, J. R. Walensky, G. Wu and T. W. Hayton, Inorg. Chem., 2013, 52, 3556.

11 H. Lauke, P. J. Swepston and T. J. Marks, J. Am. Chem. Soc., 1984, 106, 6841.

12 S. Fortier, J. R. Walensky, G. Wu and T. W. Hayton, J. Am. Chem. Soc., 2011, 133, 11732.

13 S. Fortier, B. C. Melot, G. Wu and T. W. Hayton, J. Am. Chem. Soc., 2009, 131, 15512.

14 E. R. Sigurdson and G. Wilkinson, Dalton Trans., 1977, 812.

15 (a) S. J. Kraft, P. E. Fanwick and S. C. Bart, J. Am. Chem. Soc., 2012, 134, 6160; (b) T. J. Marks and A. M. Seyam, J. Organomet. Chem., 1974, 67, 61; (c) W. G. van der Sluys, C. J. Burns and A. P. Sattelberger, Organometallics, 1989, 8, 855.

16 L. A. Seaman, P. Hrobárik, M. F. Schettini, S. Fortier, M. Kaupp and T. W. Hayton, Angew. Chem., Int. Ed., 2013, 52, 3259.

17 M. Straka, P. Hrobárik and M. Kaupp, J. Am. Chem. Soc., 2005, 127, 2591.

18 J. R. Walensky, R. L. Martin, J. W. Ziller and W. J. Evans, Inorg. Chem., 2010, 49, 10007.

19 B. E. Bursten and R. J. Strittmatter, Angew. Chem., Int. Ed., 1991, 30, 1069.

20 (a) M. D. Fryzuk, T. S. Haddad and S. J. Rettig, Organometallics, 1989, 8, 1723; (b) F. Amor, A. Butt, K. E. du Plooy, T. P. Spaniol and J. Okuda, Organometallics, 1998, 17, 5836; (c) M. Hill, G. Kehr, G. Erker, O. Kataeva and R. Frohlich, Chem. Commun., 2004, 1020; (d) M. A. Esteruelas, A. M. López, A. C. Mateo and E. Oñate, Organometallics, 2006, 25, 1448; (e) K. C. Jantunen, B. L. Scott and J. L. Kiplinger, J. Alloys Compd., 2007, 444, 363.

21 P. Hrobárik, V. Hrobáriková, A. H. Greif and M. Kaupp, Angew. Chem., Int. Ed., 2012, 51, 10884.

22 (a) See, e.g. C. A. Cruz, D. J. H. Emslie, L. E. Harrington, J. F. Britten and C. M. Robertson, Organometallics, 2007, 26, 692; (b) R. J. Butcher, D. L. Clark, S. K. Grumbine, B. L. Scott and J. G. Watkin, Organometallics, 1996, 15, 1488; (c) J. W. Bruno, G. M. Smith, T. J. Marks, C. K. Fair, A. J. Schultz and J. M. Williams, J. Am. Chem. Soc., 1986, 108, 40.

23 A. C. Albeniz, G. Schulte and R. H. Crabtree, Organometallics, 1992, 11, 242.

24 (a) See, e.g. M. Brookhart, M. L. H. Green and G. Parkin, Proc. Natl. Acad. Sci. U. S. A., 2007, 104, 6908; (b) D. Braga, F. Grepioni, E. Tedesco, K. Biradha and G. R. Desiraju, Organometallics, 1997, 16, 1846; (c) T. S. Thakur and G. R. Desiraju, J. Mol. Struct., 2007, 810, 143; (d) M. Lein, Coord. Chem. Rev., 2009, 253, 625.

25 (a) See, e.g.: H. Zabrodsky, S. Peleg and D. Avnir, J. Am. Chem. Soc., 1992, 114, 7843; (b) S. Alvarez, D. Avnir, M. Llunell and M. Pinsky, New J. Chem., 2002, 26, 996; (c) E. Cremades, J. Echeverría and S. Alvarez, Chem. - Eur. J., 2010, 16, 10380.

$26 \mathrm{H}$. Friebolin, Basic One- and Two-Dimensional NMR Spectroscopy; VCH Publishers, New York, 1991, p. 270.

27 The $C_{3}{ }^{\prime}$ optimized structure of $\left[\mathrm{Th}\left(\mathrm{C}_{6} \mathrm{H}_{5}\right)_{6}\right]^{2-}$ possesses, however, higher symmetry as compared to the solid-state molecular structure of 2 , which has four inequivalent anagostic interactions. The $C_{3}{ }^{\prime}$ structure also results from DFT optimizations of 2 without any symmetry restrictions. We also calculated similar structures (with somewhat longer Th-C bond lengths) and relative energies when performing optimizations without DFT-D3(BJ) dispersion corrections.

28 A. E. Reed, L. A. Curtiss and F. Weinhold, Chem. Rev., 1988, 88, 899.

29 The weak ortho C-H..Th anagostic interactions are also present in the $C_{3}$ geometry, but are more pronounced in $C_{3}{ }^{\prime}$ upon further distortion of the $3 \mathrm{Ph}$ rings ( $c f$. Table S6 in the $\mathrm{ESI}^{\dagger}$ ).

30 J. T. Lyon and L. Andrews, Inorg. Chem., 2005, 44, 8610. 